\title{
Familial Mediterranean fever in which Crohn's disease was suspected: a case report
}

\author{
Satohiro Matsumoto ${ }^{*}$, Shunsuke Urayoshi and Yukio Yoshida
}

\begin{abstract}
Background: Familial Mediterranean fever is a hereditary autoinflammatory disease, mainly characterized by periodic fever and serositis. The level of awareness about familial Mediterranean fever is far from sufficient, and it is assumed that there may be many patients with this disease who are under observation without an accurate diagnosis.

Case presentation: A 30-year-old Japanese man presented to us with a few years' history of recurrent episodes of fever, abdominal pain and diarrhea. He often visited a hospital when the attacks occurred; however, acute enteritis was diagnosed each time, and the symptoms resolved spontaneously within a few days. When he noticed a shortening of the interval between the attacks, he visited the hospital again. Upper endoscopy and colonoscopy performed at this hospital revealed no significant abnormal findings. He was then referred to our hospital under the suspicion of a small intestinal disease. Abdominal computed tomography revealed wall thickening and increased density of the mesenteric adipose tissue in the jejunum, which led us to suspect Crohn's disease. Oral double-balloon enteroscopy was performed; because this revealed only mild mucosal edema in the jejunum, Crohn's disease was considered to be highly improbable. Based on the patient's clinical course, we suspected familial Mediterranean fever. As the Livneh criteria for familial Mediterranean fever were satisfied, the patient was started on oral colchicine for the purpose of diagnostic treatment. A definitive diagnosis of familial Mediterranean fever was then made based on the detection of a mutation of the Mediterranean fever gene. A marked reduction in the frequency of attacks was observed in response to colchicine treatment.
\end{abstract}

Conclusions: Although Crohn's disease may be considered first in the differential diagnosis of young patients presenting with periodic fever, abdominal pain and diarrhea, the possibility of familial Mediterranean fever should also be borne in mind.

Keywords: Familial Mediterranean fever, Autoinflammatory disease, Colchicine, Crohn's disease

\section{Background}

Familial Mediterranean fever (FMF) is a hereditary periodic syndrome with autosomal recessive inheritance that is characterized by periodic fever and serositis, including peritonitis and pleuritis. FMF was first reported in 1908 by Janeway and Mosenthal [1]. It is most frequently encountered among the hereditary periodic syndromes and is estimated to affect 100,000 or more patients in the world [2]. Abdominal pain and fever are the most frequent clinical symptoms, which often makes definitive diagnosis difficult. Herein, we report our experience of a case of FMF in which a few years elapsed before a definitive diagnosis

\footnotetext{
* Correspondence: s.w.himananon@ac.auone-net.jp

Department of Gastroenterology, Saitama Medical Center, Jichi Medical University, 1-847 Amanuma, Omiya, Saitama, Saitama 330-8503, Japan
}

could be made, with the patient initially suspected as having Crohn's disease (CD).

\section{Case presentation}

A 30-year-old Japanese man presented with a few years' history of recurrent episodes of fever, abdominal pain and diarrhea that lasted for a few days and occurred a few times a year. At the time of an attack, he experienced abdominal pain spreading from the periumbilical area to the entire abdomen, a few episodes of watery diarrhea per day, and fever of approximately $38^{\circ} \mathrm{C}$, all of which were alleviated within a few days by fasting and resting. $\mathrm{He}$ often visited a medical institution when the attacks occurred; however, each time, he was diagnosed as having acute enteritis. Between attacks, the patient was 
asymptomatic and had normal stools. When he noticed that the attacks had occurred once a month for 3 months in a row, he visited the medical institution again. Upper and lower gastrointestinal endoscopy performed at the institution did not reveal any significant abnormal findings. The patient was then referred to our hospital under the suspicion of a small intestinal disease.

At the first visit, the patient presented with a fever of approximately $38^{\circ} \mathrm{C}$, abdominal pain, and a few episodes of watery diarrhea per day. As the results of the blood test at this visit, the findings of a white blood cell (WBC) count of 8,060/ $\mu \mathrm{L}$ (neutrophil [Neut]: 72.1\%), serum C-reactive protein (CRP) level of $14.64 \mathrm{mg} / \mathrm{dL}$, and erythrocyte sedimentation rate (ESR) of $39 \mathrm{~mm} / \mathrm{hr}$ suggested the presence of inflammation. He was admitted for detailed examination and treatment 1 week later. On admission, there was no fever, and the abdominal pain and diarrhea had resolved. A repeat blood test revealed a WBC count of 5,370/ $\mu \mathrm{L}$ (Neut: 53.3\%), serum CRP of $4.69 \mathrm{mg} / \mathrm{dL}$, and ESR of $29 \mathrm{~mm} / \mathrm{hr}$, showing a trend towards reduction of the inflammatory markers. Thyroid function tests and serological tests for various autoantibodies also revealed no abnormal findings.

As abdominal computed tomography (CT) revealed wall thickening and increased density of the mesenteric adipose tissue in the upper small intestine (Figure 1), we suspected CD and performed oral double-balloon enteroscopy (DBE). Although mild mucosal edema was detected in the jejunum, neither erosions nor ulcers were observed on the mucosal surface (Figure 2). A biopsy specimen obtained from the edematous mucosa of the jejunum revealed partial and slight inflammatory cell infiltration and edematous changes. As a subsequently performed transanal DBE revealed no abnormal findings, CD was considered to be highly improbable.

We suspected FMF based on the clinical course and evaluated the Livneh criteria for FMF (Table 1) [3]. Because the criteria were satisfied, oral administration of colchicine was initiated at a daily dose of $0.5 \mathrm{mg}$.
Molecular analysis for FMF was done by sequencing of exon 1 and exons of 3-10 of familial Mediterranean fever $(M E F V)$ gene. The results of genetic analysis for the $M E F V$ gene demonstrated a heterozygous mutation of M694I in exon 10. A definitive diagnosis of FMF was then made. The patient did not have any family history of the disease. Subsequently, although the attacks were not completely eliminated, their frequency markedly decreased. Only loose stools occurred for 2 to 3 days every 1 to 2 months, but there was no fever, abdominal pain, or increases of the inflammatory markers in the blood test. In order to achieve remission of the symptoms, an increase in the dose of colchicine was considered. However, because mild hepatic function impairment possibly caused by colchicine was noted, the treatment has been maintained at the initial dose. Approximately 1 year has elapsed since the initiation of the colchicine therapy, and the disease state remains stable.

\section{Discussion}

FMF is a disease with a high prevalence rate in the Mediterranean basin and is considered to be associated with the highest morbidity among the hereditary periodic syndromes [2]. In Japan, the first case of FMF was reported by Hayashi et al. in 1976 [4]. An epidemiologic study conducted in 2009 estimated the total number of patients with the disease in Japan at 292 [5]. The level of awareness about this disease is far from sufficient, and it is assumed that there may be many patients with this disease who are under observation without an accurate diagnosis.

Although the age at onset is considered to be less than 20 years in $90 \%$ of the cases, it is $19.6 \pm 15.3$ years in Japan, which is higher than that reported from overseas. Furthermore, it has been reported that in $37.3 \%$ of the Japanese cases, the disease onset occurs at the age of 20 years or later [5]. Typically, an attack starts suddenly, mainly with fever lasting for 1 to 4 days (6 to 96 hours), and abdominal pain observed in $95 \%$ or more of the cases. Diarrhea, which was observed in our patient, has been reported to occur in $10 \%$ to $20 \%$ of the patients [2].

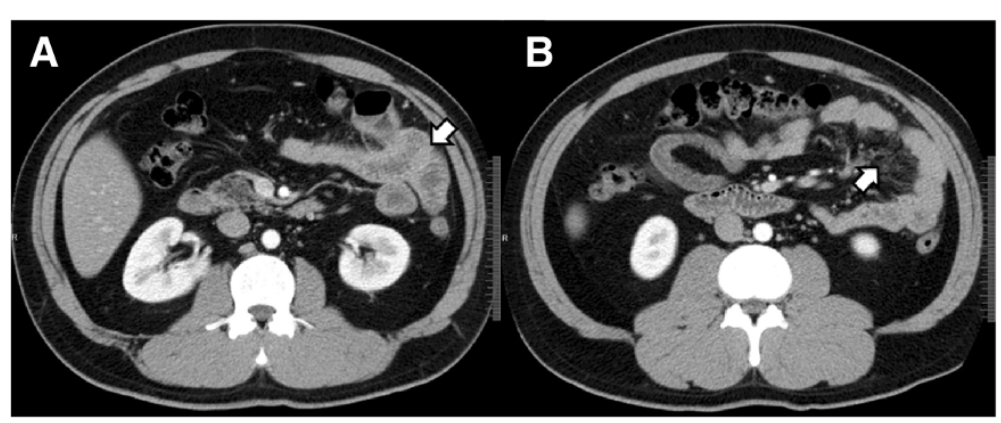

Figure 1 Findings of abdominal computed tomography (CT). A. showing a near-circumferential wall thickening in the jejunum (arrow). B. showing increased density of the mesenteric adipose tissue in the jejunum (arrow). 


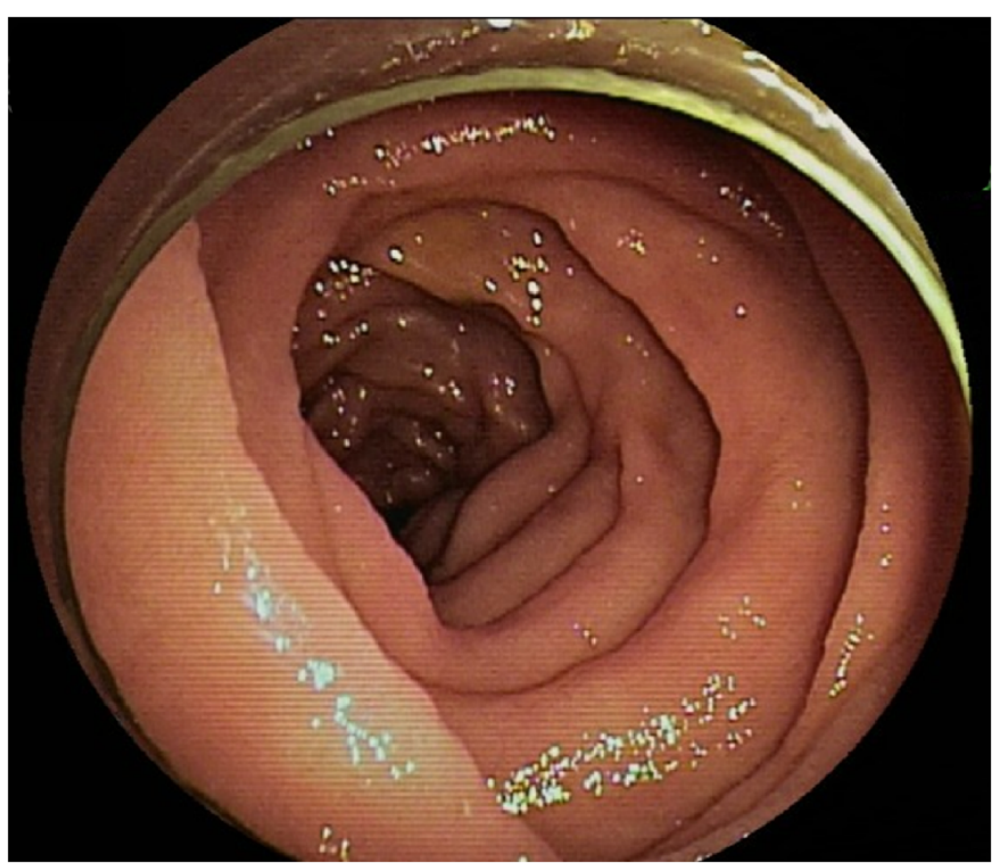

Figure 2 Findings of double-balloon enteroscopy (DBE). Oral DBE reveals mild mucosal edema in the upper segment of the jejunum.

In our patient, who presented with recurrent abdominal pain and diarrhea, small bowel CD was suspected at first, because abdominal CT revealed thickening of the upper small intestinal wall. Although blood tests revealed an increase in the levels of inflammatory markers, there was no weight loss, hypoalbuminemia, hypocholesterolemia, iron-deficiency anemia, etc. CD was definitively ruled out by DBE. On the other hand, there are reports on concurrent occurrence of FMF and CD [6-8], and also the beneficial effect of colchicine for $C D$ associated with FMF [8].

The M694I mutation was the one most frequently found in Japanese patients with FMF. The majority of the patients were compound heterozygous or complex allele for M694I mutations. The $17.5 \%$ of $M E F V$ mutations pattern were M694I alone [9]. FMF is basically an autosomal recessive disease; therefore, double mutations cause

Table 1 Diagnostic criteria for familial Mediterranean fever [3]

\begin{tabular}{|c|c|}
\hline Major criteria: typical attack* & Minor criteria \\
\hline 1. Peritonitis (generalized) & $\begin{array}{l}\text { 1. Incomplete attacks affecting } \\
\text { one or more sites }\end{array}$ \\
\hline 2. Pleurisy (unilateral) or pericarditis & -Abdomen \\
\hline 3. Monoarthritis (hip, knee, ankle) & -Lungs \\
\hline 4. Isolated fever & -Joints \\
\hline \multirow{2}{*}{$\begin{array}{l}\text { *axillary temperature }>38^{\circ} \mathrm{C} \text {, duration } \\
12-72 \mathrm{~h} \text { and } \geq \text { three attacks }\end{array}$} & 2. Exertion-related leg pain \\
\hline & 3. Response to colchicine \\
\hline
\end{tabular}

The diagnosis requires at least one major criteria or at least two minor criteria. the disease. However, the genotype of some families showed autosomal dominant inheritance of FMF [10].

Colchicine is considered to be the agent of first choice for FMF, as it is highly effective [11-14]. Furthermore, it can prevent the onset of amyloidosis, which is a complication that greatly affects the outcome, and can arrest the progression of amyloidosis even after the onset. Colchicine is also effective for the prevention and treatment of renal amyloidosis $[11,15]$.

There are few reports on the endoscopic and pathological findings of FMF. In our patient, because we found a localized lesion on abdominal CT and determined that detailed pathological examination would be required, DBE was performed instead of double-contrast examination of the small intestine. DBE only revealed mild edematous change of the small intestinal mucosal surface. Because FMF is primarily characterized by peritonitis, there may be no abnormal findings or only mild abnormalities on the mucosal surface.

Since the most common chief complaints are fever and abdominal pain, the clinical presentation of FMF is often difficult to differentiate from that of acute abdomen. Thus, it is assumed that there may be patients with FMF who unnecessarily undergo appendectomy or cholecystectomy. Because the features of Behcet's disease also sometimes satisfy the diagnostic criteria of FMF, careful diagnosis is required [9]. It is expected that many patients with FMF visit outpatient gastrointestinal clinics. In our patient, a few years had elapsed before a definitive diagnosis could be made. 


\section{Conclusions}

Although our patient was initially suspected to have CD, the disease was excluded by DBE. When patients with periodic fever or peritonitis of unknown etiology are encountered, FMF should be included in the differential diagnosis. Dissemination of information about FMF to gastroenterologists is also important.

\section{Consent}

Written informed consent was obtained from the patient for publication of this Case Report and the accompanying images. A copy of the written consent is available for review by the Editor-in-Chief of this journal.

\section{Ethical consideration}

We obtained the patient's agreement to the genetic testing, but we didn't receive ethics approval for the genetic testing.

\section{Abbreviations}

FMF: Familial Mediterranean fever; CD: Crohn's disease; WBC: White blood cell; Neut: Neutrophil; CRP: C-reactive protein; ESR: Erythrocyte sedimentation rate; CT: Computed tomography; DBE: Double-balloon enteroscopy.

\section{Competing interests}

The authors declare that they have no competing interests.

\section{Authors' contributions}

SM and SU made equal contributions to this paper. The two authors diagnosed the patient, treated the patient. SM wrote a major part of the manuscript. YY was involved in the editing of the manuscript. All authors read and approved the final manuscript.

\section{Acknowledgements}

The authors have no support or funding to report.

Received: 27 March 2014 Accepted: 23 September 2014

Published: 27 September 2014

\section{References}

1. Janeway TC, Mosenthal HO: An unusual paroxysmal syndrome, probably allied to recurrent vomiting, with a study of the nitorogen metabolism. Trans Ass Am Phys 1908, 23:504-518.

2. Onen F: Familial Mediterranean fever. Rheumatol Int 2006, 26:489-496.

3. Livneh A, Langevitz P, Zemer D, Zaks N, Kees S, Lidar T, Migdal A, Padeh S, Pras M: Criteria for the diagnosis of familial Mediterranean fever. Arthritis Rheum 1997, 40:1879-1885.

4. Hayashi A, Suzuki T, Shimizu A, Yamamura Y: Letter: Periodic fever suppressed by reserpine. Lancet 1976, 1:592.

5. Migita K, Agematsu K: Clinical aspects of Familial Mediterranean fever. Jpn $J$ Clin Immunol 2011, 34:355-360. in Japanese, Abstract in English.

6. Fidder $\mathrm{HH}$, Chowers $\mathrm{Y}$, Lidar $\mathrm{M}$, Sternberg M, Langevitz $\mathrm{P}$, Livneh A: Crohn disease in patients with familial Mediterranean fever. Medicine 2002, 81:411-416.

7. Ghaffar TYA, Elsayed SM: Colchicine resistant FMF is not always true resistance. Egypt J Med Hum Genet 2011, 12:99-101.

8. Kuloğlu Z, Kansu A, Ustündağ G, Birsin Özçakar Z, Ensari A, Ekim M: An infant with severe refractory Crohn's disease and homozygous MEFV mutation who dramatically responded to colchicine. Rheumatol Int 2012 32:783-785

9. Tsuchiya-Suzuki A, Yazaki M, Nakamura A, Yamazaki K, Agematsu K, Matsuda $M$, Ikeda S: Clinical and genetic features of familial Mediterranean fever in Japan. J Rheumatol 2009, 36:1671-1676.

10. Booth DR, Gillmore JD, Lachmann HJ, Booth SE, Bybee A, Soytürk M, Akar S, Pepys MB, Tunca M, Hawkins PN: The genetic basis of autosomal dominant familial Mediterranean fever. QJM 2000, 93:217-221.
11. Zemer D, Pras M, Sohar E, Modan M, Cabili S, Gafni J: Colchicine in the prevention and treatment of the amyloidosis of familial Mediterranean fever. N Engl J Med 1986, 314:1001-1005.

12. Dinarello CA, Wolff SM, Goldfinger SE, Dale DC, Alling DW: Colchicine therapy for familial mediterranean fever. A double-blind trial. $N$ Engl J Med 1974, 291:934-937.

13. Goldstein RC, Schwabe AD: Prophylactic colchicine therapy in familial Mediterranean fever. A controlled, double-blind study. Ann Intern Med 1974, 81:792-794

14. Tunca M, Akar S, Onen F, Ozdogan H, Kasapcopur O, Yalcinkaya F, Tutar E, Ozen S, Topaloglu R, Yilmaz E, Arici M, Bakkaloglu A, Besbas N, Akpolat T, Dinc A, Erken E, Turkish FMF Study Group: Familial Mediterranean fever (FMF) in Turkey: results of a nationwide multicenter study. Medicine (Baltimore) 2005, 84:1-11.

15. Ben-Chetrit E: Familial Mediterranean fever (FMF) and renal AA amyloidosis-phenotype-genotype correlation, treatment and prognosis. J Nephrol 2003, 16:431-434

doi:10.1186/1756-0500-7-678

Cite this article as: Matsumoto et al:: Familial Mediterranean fever in which Crohn's disease was suspected: a case report. BMC Research Notes 2014 7:678.

\section{Submit your next manuscript to BioMed Central and take full advantage of:}

- Convenient online submission

- Thorough peer review

- No space constraints or color figure charges

- Immediate publication on acceptance

- Inclusion in PubMed, CAS, Scopus and Google Scholar

- Research which is freely available for redistribution 